\title{
Manipulation in political stock markets - preconditions and evidence
}

\author{
JAN HANSEN*, CARSTEN SCHMIDT $\dagger$ and \\ MARTIN STROBEL $\ddagger$
}

Humboldt-Universität zu Berlin, Institute of Public Economics, Spandauer Str. 1, D-10178 Berlin, Germany, E-mail: jhansen@wiwi.hu-berlin.de; $\dagger$ Max Planck Institute for Research into Economic Systems, Strategic Interaction Group, Kahlaische Str. 10, $D$-07745 Jena, Germany, $\ddagger$ International Institute of Infonomics,

PO Box 2606, 6401 DC Heerlen, The Netherlands,

E-mail:Martin.Strobel@infonomics.nl

Political stock markets (PSM) are sometimes seen as substitutes for opinion polls. On the bases of a behavioural model, specific preconditions were drawn out under which manipulation in PSM can weaken this argument. Evidence for manipulation is reported from the data of two separate PSM during the Berlin 1999 state elections.

\section{INTRODUCTION}

Political stock markets (PSM) are futures exchanges on the outcome of an election. In most cases, they are organized into vote share markets - with the price of a party-contract representing the expected vote share on election day. Compared to opinion polls, PSM present a rather new instrument for the prediction of an election's outcome, though they have yielded comparatively reliable results over the last decade. Since the presidential election in 1988, with the Iowa Presidential Market predicting the outcome by $0.2 \%$ mean average error (Forsythe et al., 1992), more than $150 \mathrm{PSM}^{1}$ have been conducted in at least 14 countries (see Forsythe et al., 1999; Berlemann and Schmidt, 2001).

In the following note the impact of manipulation on PSM is analysed. On the basis of a behavioural model it is going to be shown that there is an incentive for manipulation, provided: (i) that the media is covering PSM; and (ii) that there is a situation in which a decisive vote illusion can be created. This effect is analysed on the basis of empirical data drawn from two separate PSM that ran simultaneously during the Berlin-state elections in 1999. In addition, the conflict between media coverage and prognosis quality needs to be considered. To allow for media coverage a second-best solution is presented which attempts to reduce the PSM vulnerability to manipulation.

The vulnerability of PSM to political manipulation is noticed by Bohm and Sonnegard (1999), yet they do not provide evidence. In the context of betting markets Camerer (1998) reports strategic manipulation in a field experiment.

\section{BEHAVIOURAL MODEL}

The rationale of a PSM is sketched in Fig. 1, left. The population is characterized by a latent and unobservable voting behaviour. Market participants try to acquire information about the populations voting behaviour and form beliefs about it. On the basis of the conclusions reached, traders act on the market by means of trading contracts. The contracts' market prices can serve as an indicator of the voting behaviour. In other words, the market aggregates the individual traders' beliefs with regards to the election outcome. As long as the causal dependence between voting behaviour and market prices works in one direction,

$\dagger$ Corresponding author. E-mail: cschmidt@mpiew-jena.mpg.de

${ }^{1}$ Figures were presented by Forrest Nelson at the workshop on 'Prediction Markets' in Berlin 2000. 
the prognosis seems to present a decent approximation of the real voting behaviour. Thus, any inaccuracy in the prognosis needs to be attributed to either incomplete information sampling or failures in the mental faculties of the traders. ${ }^{2}$

The situation changes substantially, when the PSM transaction prices are published via mass media and made accessible to the voters. Since the prognosis is communicated to many voters, it might have an impact on the population's overall voting behaviour. One specific reason for voters to change their voting behaviour is the impression of having a decisive vote. Even though the probability of a single vote's having a decisive influence is infinitesimally small (Owen and Grofman, 1984; Gelman et al., 1998), the voters' tendency to vote increases with the probability that their vote might actually decide the final outcome (Barzel and Silberberg, 1975). For example, if the weaker candidate in a presidential election promises to gain ground, non-voters might be mobilised to vote for him due to their illusion of having a decisive vote. In the model, the mass media together with the decisive vote illusion closes the circle of influence (Fig. 1, right). In such a situation, a party or its members might enter the market and attempt to manipulate the prices, hence the prognosis, and with that the population's voting behaviour. Due to the imperfections of the PSM, persistent manipulation of market prices is feasible. Since market participants have finite endowments, ${ }^{3}$ an unreasonable traders' influence on the market prices can only partly be neutralised by one rational player.

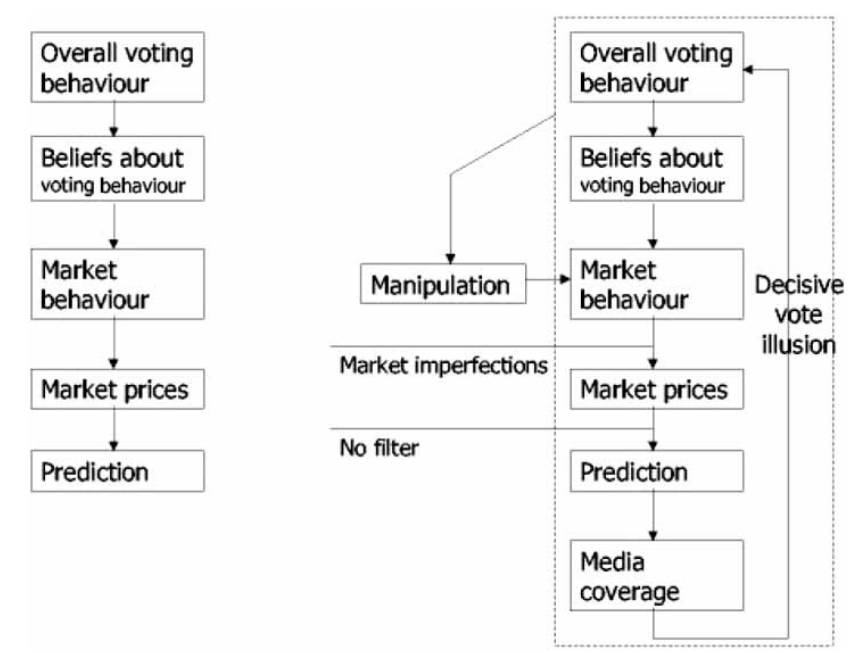

Fig. 1. Rationale of a political stock market with (right) and without (left) coverage by mass media

\section{PRECONDITIONS IN THE BERLIN 1999 STATE ELECTION}

Two independent PSM were conducted to predict the outcome of the Berlin 1999 state election: the commercial project Wahl\$treet of the daily newspapers 'Der Tagesspiegel' and 'Berliner Morgenpost', and the Wahlboerse of the Humboldt University Berlin and the daily newspaper 'Berliner Zeitung'. The Wahlboerse was open for 47 days and Wahl\$treet for 48 days, respectively. In both PSM the maximum deposit was limited to $€ 50$ per participant, and both used a continuous double auction with unit-portfolios as market institution. The Wahlboerse attracted 200 participants, while Wahl\$treet registered 561 traders.

For the six weeks that preceded the election, the three newspapers published a daily column on the first page of their local Berlin pages that included the last day's prices of the vote share-contracts. The following information was included: the market prices at 4 p.m. of the last day, the changes in last day's quotes and Wahlboerse additionally published a short comment on last day's market activity. Altogether, the three newspapers were read by about $30 \%$ of all individuals in the Berlin area. ${ }^{4}$

In 1995 the liberal FDP party did not exceed the minimum of $5 \%$ of the vote shares that are needed to be represented in parliament. Close to the election day, the FDP started to run a decisive vote campaign. The advertisements that were published in the newspaper ran as follows: 'Sensation: opinion polls see FDP to re-enter parliament! Chance for Berlin: Infratest/Dimap (pollster) one week ago: FDP at 3\%. Infratest/Dimap this week: FDP has good chances to make the 5\%-barrier. Your vote will not be lost!'.

\section{EVIDENCE OF MANIPULATION}

\section{Email}

Eleven days prior to the election day, on 29 September the headquarters of the FDP sent the following message to all members of the Berlin FDP that have access to email: ${ }^{5}$

The Tagesspiegel is publishing a PSM on a daily basis, according to which the FDP is traded at $4.23 \%$ at the moment. You find the PSM on the Internet at http:// berlin.wahlstreet.de. Many citizens do not consider the PSM as a game, but as a result of opinion polls. Hence, it is important that the price of the FDP is going to rise during the last days. As is the case with every exchange, the

\footnotetext{
${ }^{2}$ The rather naïve explanation according to which a trader's individual voting behaviour is influenced by investment decisions can be excluded.

${ }^{3}$ The maximum investment is usually limited due to legal restrictions.

${ }^{4}$ This includes non-electives. Source: MA 99, AG.MA e.V., Media Micro-Census GmbH.

${ }^{5}$ The email was forwarded to a member of the Wahlboerse team by a subscriber of the FDP member mailing list. A copy of the email (in German) can be provided on request.
} 


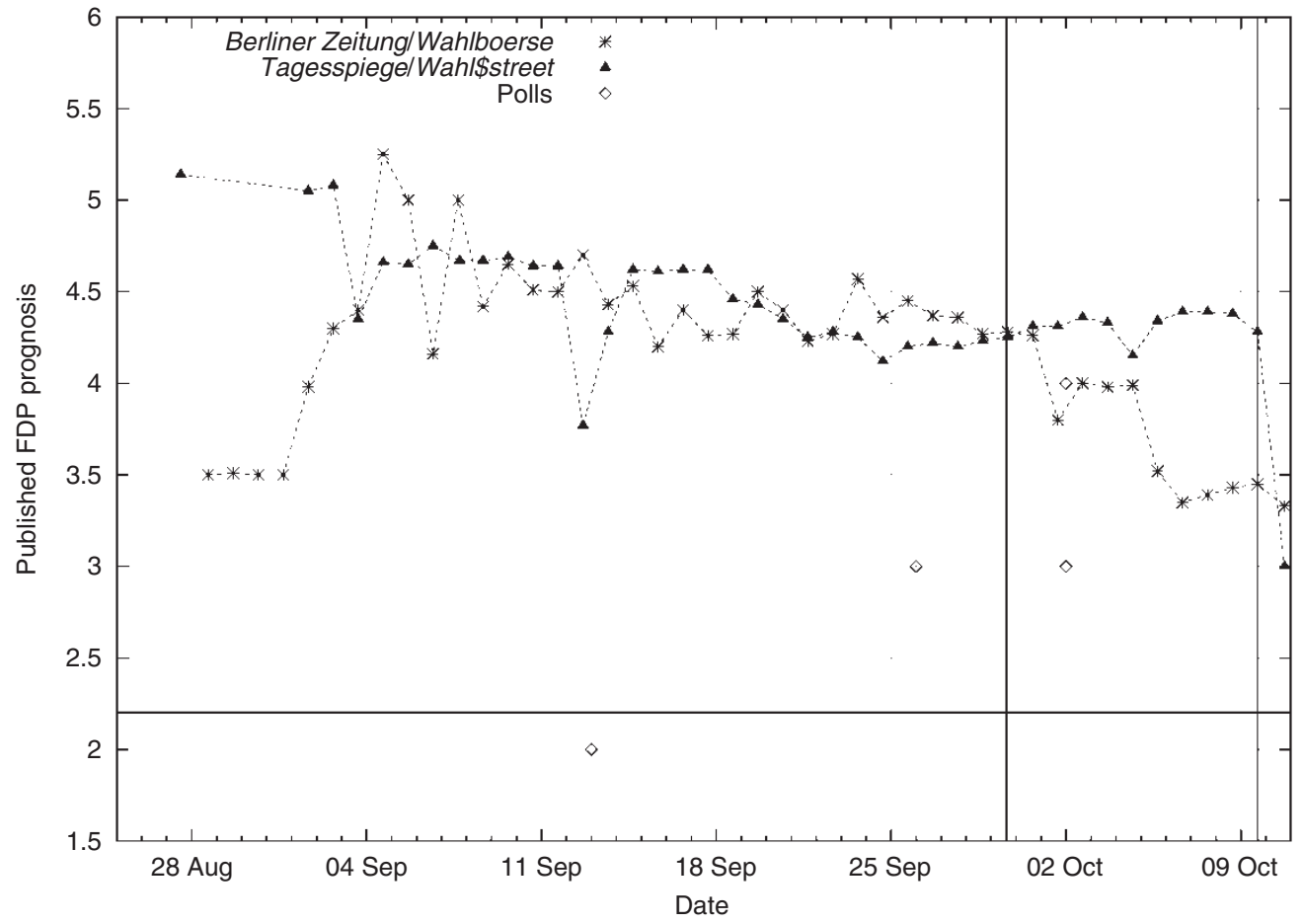

Fig. 2. Daily prognosis of FDP contracts published in Berlin newspapers

price level is a result of the demand. Please participate at the PSM and buy FDP contracts. Eventually, we are all convinced of the success of our party.

\section{Published prices}

The daily FDP quotes of the two PSM published in the newspapers are shown in Fig. 2. The four published polls conducted by three different institutes are arranged by publication date. The horizontal line represents the final vote share of the FDP on election day (2.2\%). Note, a representation in parliament requires at least a $5 \%$ share of votes. The left vertical line indicates the date of the email, while the right vertical line represents the last published prices prior to the election. The final prices given correspond to the final prognosis of the PSM, which were published in the newspaper after the election.

The significantly higher FDP price variance of Wahlboerse with regards to the daily prices $(F=1.816$; $p<0.030$ ) is to be attributed to the fact that a lower number of traders were involved. After the publication of the email the FDP prices started to increase slowly at Wahl\$treet and to decrease at Wahlboerse. After the final newspaper publications of the prices prior to election day, the FDP price fell by $30 \%$ at Wahl\$treet, whereas the FDP contract at Wahlboerse remained at about the same level. The authors own interpretation of these facts is, that due to different enrolment procedures new participants who registered at Wahl\$treet were able to trade instantly, while the same procedure at Wahlboerse took about one week. This way, it was possible for FDP members to influence prices at Wahl\$treet immediately, whereas at Wahlboerse they were able to act only at the very end.

\section{Trading behaviour}

In this paragraph, the data of Wahlboerse is examined for instances of manipulation. ${ }^{6}$ The number of trades was highest during the hour prior to the 4 p.m. prognosis, and twice as high as in the hour before and after this time range. On contract level, this effect concerns the large parties CDU and SPD and the small party FDP. Effects on the FDP contract after the publication of the email were not observed. ${ }^{7}$ Handrich and Roericht (2001) reported that party sympathiser at Wahlboerse, except for the group of FDP sympathisers, did not pay higher prices

\footnotetext{
${ }^{6}$ We were not able to receive the complete data of the Wahl\$treet market from the organiser. A regular analysis of the data of the Wahlboerse can be found in Handrich and Roericht (2001).

${ }^{7}$ Though the daily number of trades and the trade volume in FDP contracts rose after the email was sent out, the same tendency was observed with all the other contracts as well.
} 
for their house stock. ${ }^{8}$ To explore whether this behaviour is an indicator for manipulative attempts one defines a strategy for a manipulative trader. This trader functions as FDP follower by collecting only this contract on the market and not selling it until the final prognosis is published. Out of the 200 participants five traders were identified who met this criterion. There was only one trader in this group who registered after the email of the FDP, namely on 30 September, and who participated only during the last three trading days, demonstrating a price taking behaviour.

Finally, the concern is the number of manipulators that were needed to keep the FDP contract at $5 \%$ of the vote shares. One small party buyer might place limit orders to buy FDP at $€ 0.05$. As long as the number of offers to buy exceeds the number of offers to sell, the price floor of 0.05 is thus established. On the other side, selling one FDP contract requires that some trader must have purchased a unitportfolio at $€ 1$. Deducting the 0.05 payment for the FDP share means each contract sold at 0.05 requires an investment of 0.95 , thus the impact of this manipulative trader has to be counterbalanced by 19 sellers. To keep the price at $€ 0.05$ in the example of Wahlboerse, it would take seven manipulative traders with the total endowment of at least $€ 305.26$ in order to counterbalance 200 participants with an average endowment of $€ 29$. When buying all FDP contracts at 0.05 Euro, the hypothetical losses of the additional traders would rise up to $€ 134.31$.

\section{CONCLUSIONS}

From the data of the Berlin 1999 election, it can be concluded that PSM are vulnerable to manipulation. At Wahlboerse manipulative attempts related to daily newspaper publication were observed. The participation delay due to the enrolment procedure is responsible that no obvious manipulation attempts on FDP contracts can be observed. Therefore, the differences in FDP prices that were quoted in the two PSM after the email's publication are attributed to manipulation. For comparatively small contracts in particular, manipulation seems to be very effective. The vulnerability to manipulation does not exclusively apply to elections with the $5 \%$ rule, but might be detected at a presidential election with three candidates also. To avoid manipulative effects, one simple solution is the prevention of media coverage. Lately, PSM seem to have become a subject of interest to the media rather than to the scientific community. Consequently, future PSM are more likely to be covered by the media. Therefore, a second-best solution that compensates for

\footnotetext{
${ }^{8}$ The party affiliation of the participants was obtained by a questionnaire.
}

manipulation attempts is proposed: (i) the reduction of market imperfections; and (ii) the filtering of the prognosis. For electoral systems with entrance barriers it can be considered to leave small parties out and to assign their votes to the 'Rest of Field' contract. An additional winner-takesit-all market might serve as alternative, especially with regards to the decision, whether small parties should make it to the parliament or not. To analyse whether manipulation has an effect on stock prices research has to go back to the lab. First attempts have been made to capture the behavior of traders with insider information (Nöth and Weber, 1999). Last and least, the FDP of all German parties claims to have the highest economic competence. Considering the markets some evidence was found that they might be true.

\section{ACKNOWLEDGEMENTS}

The authors would like to thank Werner Güth, Robin Hanson, Forrest Nelson and the participants of the workshop on 'Prediction Markets' that took place at the Humboldt University Berlin in June 2000, for helpful comments and suggestions. They also thank Lars Handrich and Steffen Weber for writing comments published in the daily column of the Berliner Zeitung. The financial support from the German Research Foundation (DFG grant no. SFB 373/C5), the Berliner Zeitung and the Berliner Volksbank is gratefully acknowledged.

\section{REFERENCES}

Barzel, Y. and Silberberg, E. (1975) Is the act of voting rational?, Public Choice, 16, 51-8.

Berlemann, M. and Schmidt, C. (2001) Predictive accuracy of political stock markets - empirical evidence from a European perspective, Discussion paper, Sonderforschungsbereich 373, Humboldt-Universität zu Berlin.

Bohm, P. and Sonnegard, J. (1999) Political stock markets and unreliable polls, Scandinavian Journal of Economics, 101, 205-22.

Camerer, C. (1998) Can asset markets be manipulated? A field experiment with racetrack betting, Journal of Political Economy, 106, 457-81.

Forsythe, R., Nelson, F., Neumann, G. and Wright, J. (1992) Anatomy of an experimental political stock market, American Economic Review, 82, 1142-61.

Forsythe, R., Rietz, T. and Ross, T. (1999) Wishes, expectations and actions: a survey on price formation in election stock markets, Journal of Economic Behavior and Organization, 39, 83-110.

Gelman, A., King, G. and Boscardin, W. (1998) Estimating the probability of events that have never occured: when is your 
vote decisive?, Journal of the American Statistical Association, 93, 1-9.

Handrich, L. and Roericht, U. (2001) Wahlprognosen mit Wahlbörsen. Das Berliner Beispiel 1999, Zeitschrift für Parlamentsfragen, 32, 822-41.
Nöth, M. and Weber, M. (1999) Insider detection in experimental asset markets, Discussion paper, University Mannheim.

Owen, G. and Grofman, B. (1984) To vote or not to vote: the paradox of nonvoting, Public Choice, 42, 311-25. 